Warbrick, I, Came, H and Dickson, A. (Under review) The shame of fat shaming in public health: Moving past racism to embrace indigenous solutions. Critical Public Health

\begin{abstract}
Indigenous peoples in developed nations are more likely to be overweight, obese, and disproportionately affected by the comorbidities and physical disorders associated with weight when compared with their counterparts. Beyond the physical ailments are a variety of psychological, emotional, and social issues which are associated with being 'fat' and/or overweight and/or from subsequent stigmatisation.

Long before this world's populations reached the current alarming level of obesity, Māori (the indigenous people of New Zealand) were stigmatised, like so many other colonised peoples, because of the colour of their skin, their beliefs, and their culture. Stigma is nothing new to Māori, and so when we are told that we are fat and less productive (or moral) because of our 'fatness', we are not surprised because we have been told the same thing (albeit for a different reason) for generations.

Considering the relatively high proportion of Māori people who don't fit the 'recommended weight range', the justification for racism is seemingly strengthened. In this paper, we explore i) Māori and white perceptions of weight, and ii) who benefits from racism and fat-shaming. We then iii) outline New Zealand policy and practice and iv) propose indigenous solutions and measures as pathways out of fat-shaming.
\end{abstract}

Key words: indigenous, stigma, overweight, racism, health promotion, New Zealand

\title{
Introduction
}

Disney's recent animated production Moana (Clements \& Musker, 2016) created controversy by apparently depicting Maui, a Polynesian demi-god, as obese. Roy (2016) reported in the Guardian that social media was a flutter with outrage at the negative racial stereotyping. We contend that Maui is depicted as large, strong and resourceful; a demi-god that we can be assured hasn't eaten 'fast food' for a thousand years - having been trapped on a deserted island. Whether Maui is obese is irrelevant to the mana wahine (strong woman) story of Moana, but this social media episode amplified indigenous fatigue at racial stereotyping and fat-shaming.

Fat shaming frequently has a racist edge, and is most openly expressed as weight stigma (Brochu \& Esses, 2011). Rand and Macgregor (1991) in their survey of patients who had lost significant weight as a result of gastric bypass surgery, showed that all those surveyed would rather be a normal weight than a multimillionaire, and most would rather lose a leg, have heart disease and be deaf than gain back weight. Almost four decades on and weight anxiety is more entrenched in society than ever and much of it is expressed, particularly by those on 'higher (thinner) ground' in the form of shaming. This can even be seen in the 'pedagogy of disgust' that pervades anti-obesity public health campaigns (Lupton, 2015).

$\mathrm{We}$, an indigenous and two white academics, note that sticks and stones will break bones, bruise muscles and break skin, but critically, names and stereotypes hurt feelings and sap energy. Through the obesity epidemic, body size has become a focus for public health interventions, and we argue that fat shaming, in the context of Māori, seems to be a manifestation of entrenched societal racism. In this conceptual paper, we explore i) Māori and white perceptions of weight, ii) who benefits from racism and fat-shaming, iii) New Zealand policy and practice concerning weight, and then iv) propose indigenous solutions and measures as pathways out of fat-shaming.

\section{Perceptions of weight}

White people and weight

Wallis, Duchess of Windsor is credited with coining the expression that "you can never be too rich or too thin". Certainly white western socio-cultural beliefs encourage women to strive to be thin (Ngamanu, 2006). To be thin is seen to be positive, in control of your body, to show discipline and self-care. Being fat is constructed as a negative, a failure; it is associated with being lazy - you have let yourself go. This dominant discourse has been promoted through beauty pageants, the cult of the supermodel, Hollywood and popular women's magazines. 
Orbach (1988) in her pioneering psychoanalytical text, rejected this dominant discourse and argued as per her title that Fat is a Feminist Issue. She argued media pressure on women has led women to be dissatisfied with their bodies and this insecurity has fuelled dieting and over-eating. Building on this work, Wolf (1991) in the Beauty Myth argued that as women's social power has increased the pressure on women to adhere to unrealistic standards of beauty that are manipulated and fuelled by the billion-dollar beauty industry. Pause (2015) is part of an international fat movement that focuses on challenging anti-fat attitudes and their impact on the health and well-being of fat people. She argues within the dominant (white) "...culture there is only one kind of body and only one kind of lifestyle that is acceptable”. However, we feel that 'Fat is [also] a Racism Issue', and just as sexism-related stigma is compounded by weight anxiety, racism toward Māori is compounded by fat-shaming.

Within the context of the health sector the body mass index (BMI) has become the dominant global measure used to define healthy weight. It classifies populations as underweight, normal, overweight and obese; overweight being defined as having a BMI equal to or more than 25 , and obesity as a BMI equal to or more than 30 (World Health Organization, 2017). Duncan, Duncan, and Schofield (2010), based on their study of five ethnic groups, developed ethnic specific measures of overweight, yet even these do not account for interindividual variations in muscle mass, bone density, and other variations in body type. Because of this variation (even within one ethnicity), issues can arise when BMI, which correlates to population data on health status, is used at an individual level (i.e. a routine check-up with your doctor) as an indicator of health. For example, a healthy Māori male with a relatively high muscle mass and low percentage of body fat, could be incorrectly 'labelled' as high-risk for heart disease and diabetes.

\section{Māori and weight}

The notion of weight gain or weight loss was almost non-existent among Māori, until white colonisers 'intervened' in Māori ways of life. In the early stages of colonisation it was warfare and communicable diseases brought by the colonisers which destroyed the health and lives of many indigenous people (Dow, 1999). Now, a wave of non-communicable diseases - such as diabetes and heart disease (Robson \& Harris, 2007), also brought by the colonisers by way of non-traditional foods and lifestyles, plague Māori.

The body of literature highlighting the 'heaviness of indigeneity', that is the disproportionate prevalence of overweight among Indigenous peoples in colonised countries, is relatively unhelpful (Kolahdooz, Sadeghirad, Corriveau, \& Sharma, 2017). Māori have heard the 'alarming' statistics and have experienced the stigma that results from those findings in their interactions with health professionals and agencies for decades. Indeed the governments, (and civil societies) long standing 'war on obesity' ("NZ govt declares war on obesity," 2007) could be seen as a war on Māori.

Yet, this deficit approach, driven by the fear of 'shocking' statistics appears to have led to no largescale improvements. A handful of exceptions have emerged - If they can do it... why aren't the rest of you? While some may see these success-stories as breaking the cycle, underneath the before and after pictures is the perpetuation of a higher (white) moral ground. Indigenous people (minus the exceptions) continue to languish in their overweight state, waiting for the heroic white (wo)man (the personal trainer, the nutritionist, the general practitioner, the producer of the newest weight loss product...) to save us - we who are incapable of saving ourselves.

Indigenous solutions highlight the value of traditional knowledge, values, and beliefs in addressing contemporary issues. The Atua Matua Māori health framework, (Warbrick, Dickson, Prince, \& Heke, 2016) provides an alternative to weight-focused health promotion. Likewise, Maunga ki te Tangata is another approach which acknowledges the health-determining connection of individuals to their environment, social structures, and family.

\section{Racism toward Māori}

Racism stepped ashore in New Zealand with the arrival of white people and the subsequent waves of colonisation. The political and economic processes of colonisation, whereby one nation assumes it has a right to take over another nation is inherently racist (Jackson, 1995). The colonising nation assumes it has a more sophisticated culture and superior legal, education and health systems. Kirkwood, Liu and Weatherall (2005), 
argue although colonisation is often something described in the past, it continues to shape contemporary realities.

Colonisation is an example of institutional racism in that it is pattern of differential access to goods services and opportunities by race; whereby one group is disadvantaged while another is advantaged. Jones (2000) argues institutional racism is codified in social institutions. Research has identified racism in the administration of the social welfare system (Ministerial Advisory Committee, 1988), criminal justice system (Workman, 2011), and public health system.

Societal racism is the process of ascribing negative attributes to a culture and then having the power to enact those prejudices. McCreanor et al's (2014) have argued routine negative media coverage fuels negative stereotypes and discourses about Māori. McCreanor and Nairn (2002) have mapped how Tauiwi (settler) general practitioners talk about Māori health. They found constructions that blame Māori for their plight and/or justified the existing service provision. Penney, Barnes and McCreanor (2011) found clinicians described Māori patients as non-compliant. This non-compliance was explained as Māori ignorance, poverty and selfdestructiveness. Māori patients in contrast described proactively pursuing health. Wilson and Barton (2012) found Māori patients accessing health services felt marginalised and had negative experiences within generic services.

\section{Who benefits from racism and fat-shaming}

Central to understandings of institutional and societal racism is the notion that while one group is disadvantaged another (white people) are advantaged. The notion of the superiority of whiteness is a flawed, modifiable social construct. McIntosh (1988) in her landmark essay, argued that all white people receive unearned white privileges. This often takes the form of greater influence, and expedited access to power and resources. Addy (2008) argued white people get to be "normal" and other groups are defined against this monocultural centre. It is important to note privilege and/or racism is often intermeshed with other systems of oppression such as class, sexism, heterosexism which compound advantage or disadvantage (Crenshaw, 1991).

Fat shaming indigenous people serves to ideologically maintain the hegemonic (mono-cultural) discourses of indigenous failure. Indigenous people are often presented as hapless and unable to engage in either individual or collective self-care. From a public health perspective, this ideology directly conflicts with indigenous health promotion philosophies as articulated by Ratima (2001), and Durie (1999) that emphasise culturally tailored approaches, the pursuit of tino rangatiratanga (sovereignty) and addressing the wider determinants of health. Came's (2014) work shows that within health policy in New Zealand indigenous evidence about what works for Māori communities is often overlooked in favour of data from the global north which rarely has indigenous analysis. This distrust and suspicion of Māori is also reflected in how Māori health providers are treated by health funders (Came, 2012; Came, Doole, McKenna, \& McCreanor, Under review).

The 'war on obesity' (Boswell, 2016) waging in most developed countries has led to an increased fear of being or becoming overweight and the market has benefited greatly from this, fuelling multi-billion dollar 'big food' and 'big pharma' industries (Williams \& Nestle, 2016). Gyms, dietary supplements, and 'health' food companies are maintained and expanded by this 'weight anxiety' (Dickson, 2011). We contend that health systems and the government's that fund them, who are faced increasingly with public concerns about limited health resources and funding, can redirect blame back to individual failing - the 'cash cow' of the weight loss industry. This diverts attention from policies which favour 'commercial interest' over health, with weak restrictions on the sale and marketing of certain types of food. But perhaps restrictions would not be so weak if the coloniser rather than Indigenous peoples who had the high prevalence of obesity related illnesses? Either way, individual (or Indigenous) blaming for 'the weight issue' has not led to large-scale improvements in health outcomes or investment in indigenous solutions.

\section{New Zealand policy and practice}

The Healthy Eating Health Action (HEHA) (Ministry of Health, 2003) strategy has informed much New Zealand public health work in this space. Underneath this policy framework are service specifications which inform the detail of contract negotiations between health funders and providers. HEHA and relevant 
service specification (Ministry of Health, 2016) are framed around the Ottawa Charter for Health Promotion (World Health Organization, 1986, November). Problematically the Charter contains no reference to indigenous peoples, indigenous worldviews or aspirations. The specification (Ministry of Health, 2016, p. 4) assures "providers will be supported and encouraged to deliver health promotion activity using kaupapa Māori approaches". However providers are strongly encouraged to utilise results based accountability (RBA) (Friedman, 2005). RBA being the central platform of the government's procurement and contracting processes and their preferred evaluation framework. RBA was developed in the United States and anecdotal feedback suggests it is an uncomfortable fit with Māori values and worldviews.

Within lifestyle health promotion, weight remains the primary outcome measure in interventions targeting Māori. Physical health is the primary focus, with limited mention of psychological, spiritual, or whānau well-being. A focus on BMI and weight seems to channel health promotion into the mono-cultural status quo. This tension seems to be fuelled by the promotion of RBA to assess the success of such initiatives without consideration of Māori values. In the Māori outcome and evaluation literature 'healthy weight' is not often alluded to though some would argue it is an implicit part of physical aspects of well-being.

Over the past three decades, a renaissance of Māori knowledge has emerged and grown in momentum. Māori have developed a plethora of Māori-centred outcome measures, indicators and evaluation tools. For instance, Fitzgerald and Durie (2000) and Durie, Fitzgerald, Kingi, McKinley, and Stevenson (2002) have developed tools for assessing and addressing Māori outcome from their longitudinal study of Māori household. Kingi and Durie (2000) and Kingi (2002) have done extensive work around Māori mental health outcome measures. Likewise, kaupapa Māori evaluation is an unfolding speciality within in public health (Kerr, Penney, Moewaka Barnes, \& McCreanor, 2010; Masters-Awatere, 2015).

The authors believe that Māori and indigenous knowledge needs to be embraced within public health work. Prioritising Māori-valued outcomes over (politically-driven) neoliberally-valued outcomes is vital. Weight loss, should be a secondary incidental outcome, if an outcome measure at all, to the activities of reconnection and decolonisation of Māori people and of the systems which continue to oppress them. It doesn't make sense to keep focusing on an outcome which research confirms is extremely difficult to change, or near impossible to achieve for some (Aphramor, 2005; Gluckman \& Hanson, 2012).

Secondly, a shift is needed from fat-shaming individuals and specific groups who are predominantly larger (individual responsibility) to understanding the systemic impacts of colonisation (structural discrimination and violence) on the colonised. Thus, decolonisation and engagement with whakapapa (geneaology) - acknowledges ones place within the environment including one's own experiences and the experiences of ancestors could be the key to improving the health (and reducing the 'weight-related' illnesses) of Māori. Such a reorientation would also require reallocation of public health resources in terms of investment in Māori solutions.

Tomiyama and Mann (2013) point out in the title of their paper, "If shaming reduced obesity, there would be no fat people." Trying to solve the 'obesity issue' with an approach shaped by the same frame of reference which has led to the issue in the first place, is not the way forward. Instead, it requires looking back critically at those systems and practices in place when these groups had near perfect health and find innovative ways to bring those things into a contemporary setting.

\section{Conclusion}

The near universal use of western-orientated outcome measures highlight societal racism and an unwillingness of the health system to accept Māori knowledge at all levels and stages of health service provision. Although Māori-driven outcome measures have been addressed in other fields, such as mental health, when it comes to initiatives targeting 'physical' aspects, government agencies require assessment criteria which conforms to maintaining the weight focused norm i.e. "we'll let you design the solution, but we won't let you measure the outcomes which are most meaningful to you". 
Societal and institutional racism needs to be challenged within the nutrition, physical activity and weight loss space. Allies need to challenge racism in all its forms and embrace anti-racism praxis. We welcome indigenousled solutions informed by indigenous knowledge.

We began with Maui and the stir caused by his body as depicted in Disney's Moana. However, rather than an expression of stereotype and racism, we feel that this depiction of a 'brown' hero is exactly what is needed for public health messages; a celebration of an active, resilient, powerful figure whose body does not align with a Euro-western ideal body shape. In the movie, Maui's health and mana (prestige) is suffering only because of a lost connection to his environment, which is restored once he realigns himself within that ecosystem in service of Moana's quest to restore balance between environment and people. Here fiction provides a vision for a future where indigenous ways provide solutions to the issues that have arisen through colonisation of Indigenous peoples. 


\section{References}

Addy, N. (2008). White privilege and cultural racism: Effects on the counselling process. New Zealand Journal of Counselling, 28(1), 10-23. Retrieved from http://www.nzac.org.nz/nzjc.html

Aphramor, L. (2005). Is a weight-centred health framework salutogenic? Some thoughts on unhinging certain dietary ideologies. Social Theory and Health, 3(4), 315-340. doi:10.1057/palgrave.sth.8700059

Boswell, J. (2016). The real war on obesity: Contesting knowledge and meaning in a public health crisis. London, England: Palgrave Macmillan.

Brochu, P. M., \& Esses, V. M. (2011). What's in a name? The effects of the labels 'fat' versus 'overweight' on weight bias. Journal of Applied Social Psychology, 41(8), 1981-2008. doi:10.1111/j.15591816.2011.00786.x

Came, H. (2012). Institutional racism and the dynamics of privilege in public health. (Unpublished doctorate), Waikato University, Hamilton, New Zealand.

Came, H. (2014). Sites of institutional racism in public health policy making in New Zealand. Social Science and Medicine, 106(0), 214-220. doi:10.1016/j.socscimed.2014.01.055

Came, H., Doole, C., McKenna, B., \& McCreanor, T. (Under review). Institutional racism in public health contracting: Findings of a nationwide survey from New Zealand.

Clements, R., \& Musker, J. (Writers). (2016). Moana. In O. Shurer (Producer). United States: Walt Disney Studios.

Crenshaw, K. (1991). Mapping the margins: Intersectionality, identity politics, and violence against women of color. Stanford Law Review, 43(6), 1241-1299.

Dickson, A. (2011). The jouissance of the Lard(er): Gender, desire and anxiety in the weight-loss industry. Culture and Organization, 17(4), 313-328. doi:10.1080/14759551.2011.590307

Dow, D. (1999). Maori health and government policy 1840 - 1940. Wellington, New Zealand: Victoria University Press in association Department of Internal Affairs.

Duncan, J. S., Duncan, E. K., \& Schofield, G. (2010). Ethnic-specific body mass index cut-off points for overweight and obesity in girls. New Zealand Medical Journal, 123(1311), 22-29.

Durie, M. (1999). Te pae mahutonga: A model for Māori health promotion. Health Promotion Forum Newsletter, 49, 2-5.

Durie, M., Fitzgerald, E., Kingi, T. K., McKinley, S., \& Stevenson, B. (2002). Māori specific outcomes and indicators. Wellington, New Zealand: Te Puni Kōkiri.

Fitzgerald, E., \& Durie, M. (2000). Assessing and addressing Maori outcomes: Preliminary findings from te hoe nuku roa Maori household research. New Zealand Population Review, 26(1), 115-121.

Friedman, M. (2005). Trying hard is not good enough: How to produce measurable improvements for customers and communities. Victoria, Canada: Trafford

Gluckman, P. D., \& Hanson, M. A. (2012). Fat, fate, and disease : why exercise and diet are not enough. Oxford, England: Oxford University Press.

Jackson, M. (1995). Maori, Pakeha and politics: the Treaty of Waitangi sovereignty as culture, culture as sovereignty: Maori politics and the Treaty of Waitangi. Paper presented at the Global Cultural Diversity Conference, Sydney Australia. http://www.immi.gov.au/media/publications/multicultural/confer/13/speech56a.htm

Jones, C. (2000). Levels of racism: A theoretical framework and a gardener's tale. American Journal of Public Health, 90(8), 1212-1215. doi:10.2105/AJPH.90.8.1212

Kerr, S., Penney, L., Moewaka Barnes, H., \& McCreanor, T. (2010). Kaupapa Maori action research to improve heart disease services in Aotearoa, New Zealand Ethnicity and Health, 15(1), 15-31. doi:10.1080/1355850903374476

Kingi, T. K. (2002). Hua oranga best outcomes for Māori (Unpublished doctoral thesis), Massey University, Palmerston North, New Zealand.

Kingi, T. K., \& Durie, M. (2000). "Hua oranga": A Maori measure of mental health outcome (TPH 00/01) (pp. 1-88). Retrieved from Massey University website: http://www.earlypsychosis.org.nz/PDF/NZ/HuaOranga.pdf 
Kirkwood, S., Liu, J., \& Weatherall, A. (2005). Challenging the standard story of indigenous rights in Aotearoa/New Zealand. Journal of Community and Applied Social Psychology, 15(6), 493-505. doi: $10.1002 /$ casp. 837

Kolahdooz, F., Sadeghirad, B., Corriveau, A., \& Sharma, S. (2017). Prevalence of overweight and obesity among indigenous populations in Canada: A systematic review and meta-analysis. Critical Reviews in Food Science \& Nutrition, 57(7), 1316-1327.

Masters-Awatere, B. (2015). "That's the price we pay": Kaupapa Māori programme stakeholder experiences of external evaluation. (unpublished Phd), Waikato, Hamilton, New Zealand.

McCreanor, T., \& Nairn, R. (2002). Tauiwi general practitioners explanations of Maori health: Colonial relations in primary healthcare in Aotearoa/ New Zealand? Journal of Health Psychology, 7(5), 509518. doi:10.1177/1359105302007005670

McCreanor, T., Rankine, J., Moewaka Barnes, A., Borell, B., Nairn, R., \& McManus, A.-L. (2014). The association of crime stories and Māori in Aotearoa New Zealand print media. Sites, 11(1), 121-144. doi:10.11157/sites-vol11iss1id240

McIntosh, P. (1988). White privilege: Unpacking the invisible knapsack: Working paper 189. Peace and Freedom, 10(2), 1-2. Retrieved from http://www.areteadventures.com/articles/white_privilege unpacking the invisible_napsack.pdf

Ministerial Advisory Committee. (1988). Puao te ata tu (Day break). Wellington, New Zealand: Department of Social Welfare.

Ministry of Health. (2003). Healthy eating - healthy action: Oranga kai - oranga pumau: A strategic framework Retrieved from http://www.moh.govt.nz/moh.nsf/0/6088A42CFAA9AC6FCC256CE0000DAE66/\$File/hehastrategicframework.pdf

Ministry of Health. (2016). Public health services health promotion tier two service specification. Retrieved from http://nsfl.health.govt.nz/service-specifications/current-service-specifications/public-healthservice-specifications

Ngamanu, R. (2006). Body image attitudes amongst Maori and Pakeha females. (Masters of Social Science), University of Waikato, Hamilton, New Zealand.

NZ govt declares war on obesity. (2007). Retrieved from http://www.stuff.co.nz/national/politics/35576

Orbach, S. (1988). Fat is a feminist issue. Isle of Man: Arrow Books.

Pause, C. (2015). Opinion: A matter of fat. Retrieved from https://www.massey.ac.nz/massey/aboutmassey/news/article.cfm?mnarticle uuid=743E9418-05AE-08EA-C59A-43D31FB7638C

Penney, L., Moewaka Barnes, H., \& McCreanor, T. (2011). The blame game: Constructions of Māori medical compliance. AlterNative: An International Journal of Indigenous Scholarship, 7(2), 123-136.

Rand, C. S., \& Macgregor, A. M. (1991). Successful weight loss following obesity surgery and the perceived lability of morbid obesity. International Journal of Morbid Obesity, 15(9), 577-579.

Ratima, M. (2001). Kia urūru mai a hauora: Being healthy, being Maori: Conceptualising Maori health promotion. (Unpublished Doctoral dissertation), Otago University, Dunedin, New Zealand.

Robson, B., \& Harris, R. (Eds.). (2007). Hauora: Māori standards of health IV. A study of the years 2000-2005. Wellington, New Zealand: Te Rōpū Rangahau Hauora a Eru Pōmare, University of Otago.

Roy, E. (2016, 27 June). Disney depiction of obese Polynesian god in film Moana sparks anger. The Guardian. Retrieved from https://www.theguardian.com/world/2016/jun/27/disney-depiction-of-obesepolynesian-god-in-film-moana-sparks-anger

Tomiyama, A. J., \& Mann, T. (2013). If Shaming Reduced Obesity, There Would Be No Fat People...Callahan D, 'Obesity: Chasing an Elusive Epidemic,' Hastings Center Report, 2013 Jan; 43(1): 34-40. Hastings Center Report, 43(3), 4-5. doi:10.1002/hast.166

Warbrick, I., Dickson, A., Prince, R., \& Heke, I. (2016). The biopolitics of Māori biomass: towards a new epistemology for Māori health in Aotearoa/New Zealand. Critical Public Health, 26(4), 394-404. doi:10.1080/09581596.2015.1096013

Williams, S. N., \& Nestle, M. (2016). Big Food : critical perspectives on the global growth of the food and beverage industry. London, England: Routledge. 
Wilson, D., \& Barton, P. (2012). Indigenous hospital experiences: a New Zealand case study. Journal of Clinical Nursing, 21(15/16), 2316-2326. doi:10.1111/j.1365-2702.2011.04042.x

Wolf, N. (1991). The beauty myth. London, England: Vintage.

Workman, K. (2011). Māori over-representation in the criminal justice system does structural discrimination have anything to do with it?: A discussion paper. Rethinking Crime and Punishment. Wellington, New Zealand. Retrieved from

http://www.rethinking.org.nz/assets/Newsletter_PDF/Issue 105/01_Structural Discrimination in the CJS.pdf

World Health Organization. (1986, November). Ottawa charter for health promotion Proceedings of the 1st international conference on health promotion Ottawa, Canada: World Health Organization.

World Health Organization. (2017). BMI classification. Retrieved from http://apps.who.int/bmi/index.jsp?introPage=intro_3.html

Word count: 3976 